九州大学学術情報リポジトリ

Kyushu University Institutional Repository

\title{
Environmental Efficiency of Ecologically Engineered Rice Production in the Mekong Delta of Vietnam
}

\section{Tu, Vo Hong}

Laboratory of Environmental Economics, Graduate School of Bio-resources and Bio-environmental Science, Kyushu University

Yabe, Mitsuyasu

Laboratory of Environmental Economics, Department of Agricultural and Resource Economics, Faculty of Agriculture, Kyushu University

Trang, Nguyen Thuy

Department of Rural Socio-Economics, College of Rural Development, Can Tho University

Khai, Huynh Viet

Department of Environmental and Resource Economics, School of Economics and Business Administration, Can Tho University

https://doi.org/10.5109/1543414

出版情報：九州大学大学院農学研究院紀要. 60 (2)，pp.493-500，2015-09-18. Faculty of Agriculture, Kyushu University

バージョン :

権利関係 : 


\title{
Environmental Efficiency of Ecologically Engineered Rice Production in the Mekong Delta of Vietnam
}

\author{
Vo Hong TU ${ }^{1}$, Mitsuyasu YABE*, Nguyen Thuy TRANG ${ }^{2}$ and Huynh Viet Khai ${ }^{3}$ \\ Laboratory of Environmental Economics, Division of International Agricultural Resource Economics and \\ Business Administration Department of Agricultural and Resource Economics, \\ Faculty of Agriculture, Kyushu University, 812-8581, Japan \\ (Received April 13, 2015 and accepted May 19, 2015)
}

\begin{abstract}
Ecologically engineered rice cultivation was first introduced in the Mekong Delta of Vietnam in 2009. Although such cultivation is essential for environmental protection, the diffusion rate of the model was considered to be low. The low rate of diffusion is probably associated with the insufficient evidence about potential environmental benefits. Hence, this study applied the stochastic frontier analysis to estimate and compare the environmental, technical and pesticide use efficiency of ecological rice with those of normal rice. We conducted the survey by face-to-face interviewing 74 ecological rice farmers and 125 normal rice farmers in An Giang Province. Results revealed that the pesticide cost of ecological rice was appreciably lower than that of normal rice while the output was insignificantly different. The environmental efficiency of ecological rice was estimated about $85.54 \%$ and $84.54 \%$ for normal rice. Further, the technical efficiency of ecological rice and normal rice were $92.24 \%$ and $92.17 \%$, respectively. The eco rice had a significantly higher pesticide use efficiency than the normal rice. Our findings suggest that the introduction of ecological engineering into rice production had positive impacts on the environmental and technical efficiency.
\end{abstract}

Key words: environmental efficiency; stochastic frontier analysis; ecological engineering

\section{INTRODUCTION}

With an annual cultivated area of 4.3 million hectares, rice is one of the major crops in the Vietnamese Mekong Delta (VMD). The VMD annually contributes more than $50 \%$ (about twenty-five million tons in 2013) of total rice production in Vietnam and earned more than USD 2 billion from exports in 2013 (GSO, 2013). The VMD, a "rice bowl" of Vietnam, was also approved by the Prime Minister to be one of the four regions to ensure national food security.

Despite being blessed with ideal weather conditions and good irrigation systems, water pollution from rice production, overuse of agro-chemicals (Dung \& Dung, 1999; Ecobichon, 2001) and outbreaks of brown plant hoppers (Heong KL, 2009) caused considerable damage to the VMD's ecological system and contributed to public health issues.

Owing to the importance of rice production as a means of livelihood for the majority of the population of the VMD, environmental protection is one of the first priorities in the region. In 2009, the use of ecological engineering in rice production (abbreviated as eco rice production hereafter) was firstly introduced in the Tien Giang Province through the Rice Plant Hopper Project, which was technically coordinated by the International

\footnotetext{
Laboratory of Environmental Economics, Graduate School of Bio-resources and Bio-environmental Science, Kyushu University

Department of Rural Socio-Economics, College of Rural Development, Can Tho University

Department of Environmental and Resource Economics, School of Economics and Business Administration, Can Tho University

* Corresponding author (E-mail: yabe@agr.kyushu-u.ac.jp)
}

Rice Research Institute (IRRI) and financially supported by the Asian Development Bank. Methodologically, ecological engineering, which is a biological control based approach, requires farmers to cultivate flowering plants around the periphery of paddy fields to attract more natural enemies or beneficial organisms. Those natural enemies contribute to suppress pest populations under damaging levels. Farmers therefore use lower pesticides. After the first introduction, the model was expanded to other provinces because evidence showed despite higher labor cost for flower planting, the use of pesticides was much lower leading to lower total production cost for eco rice production (PPDAG, 2012). However, since the added economic and environmental benefits of this eco rice model are not awareness or underestimated, the model does not receive strong supports from local authorities and thus the coordination between them and the Rice Plant Hopper Project was low. As a result, the popularity of the eco rice model is low and some farmers do not want to apply this model.

According to Belbase and Grabowski (1985) and Shapiro and Müller (1977), the application of existing technologies was more cost-effective than the introduction of new ones if farmers were using existing methods inefficiently. However, the studies on the specific reduction of environmentally detrimental inputs (referred to as bad inputs hereafter) at the production possibility frontier, which means reducing bad inputs while increasing output, did not consider the VMD even though the eco rice production model was considered to be environmentally and economically efficient (Heong KL, 2009; PPDAG, 2012).

In recent years, some studies have focused on the technical efficiency (TE), which means the ability to reduce both normal and bad inputs, conditional on 
observed level of output in case of input-oriented TE or the ability to maximize output level, conditional on observed level of inputs in case of output-oriented TE of rice production in Vietnam. Kompas (2004) used panel data from 60 provinces in Vietnam for 1991-1999 and stochastic frontier analysis to estimate such TE. The study showed that the average TE of rice production was $59.2 \%$, and increased from 55\% in 1991 to $65 \%$ in 1999, while the estimated TE in the VMD was about 78\% in 1999. However, this study was limited in scope, as it did not consider TE at the farm level. By contrast, Khai and Yabe (2011) used stochastic frontier analysis and farm-level data from the 2006 Vietnam Household Living Standards Survey to estimate the TE of 3,733 farmers. In their study, the mean TE was $81.6 \%$, which is higher than that of Kompas (2004). Although these studies estimated the TE (the ability to reduce both normal and bad inputs together) of rice production in Vietnam, neither of them considered environmental efficiency (EE).

Environmental pollution as undesirable outputs was first introduced by Pittman (1983), followed by Färe et al. (1989). Pittman (1981) was also the first to propose pollution as an input vector. This approach was applied and modified by Reinhard et al. (1999) and Reinhard and Thijssen (2000). They have defined EE as the ratio of the feasible minimum to observed levels of bad inputs, conditional on observed levels of outputs and normal inputs. In other words, EE is the ability to reduce bad inputs to optimal levels while holding output and normal inputs constant.

Following those studies and the earlier-stated problems in eco rice production, this study aims at measuring and comparing $\mathrm{EE}$ of eco rice farmers in terms of the potential reduction of bad input vectors, that is, the possibilities of reducing bad inputs to those of traditional rice, using stochastic frontier analysis. The remainder of this paper is structured as follows: Section 2 describes the analytical framework and data collection procedure. Section 3 discusses the empirical results and compares the environmental and technical efficiencies between eco and normal rice. Section 4 presents a summary and conclusions.

\section{METHODOLOGY}

To measure and compare comprehensive EE scores of eco rice farmers to those of normal rice, we use stochastic frontier analysis. The detailed way to estimate EE scores for each farmer is descripted as follows:

A firm is assumed to use two types of inputs, $X$ and $Z$, to produce a single output $Y\left(Y \in R_{+}\right)$, where $X\left(X \in R_{+}\right)$ contains normal input vectors and $Z\left(Z \in R_{+}\right)$are bad input vectors that adversely affect the environment.

The stochastic production function is defined as follows:

$$
Y_{i}=f\left(X_{i}, Z_{i}, \beta, \alpha, \delta\right) \exp \left(v_{i}-u_{i}\right)
$$

where $\beta, \alpha$ and $\delta$ are parameters to be estimated; $v_{i}$ is a symmetric independently and identically distributed (i.i.d) random error term $\left(v_{i} \sim N\left[0, \sigma_{v}^{2}\right]\right)$ that represents exogenous effects beyond the farmers' control (e.g., the impact of adverse weather, natural disasters, and acts of God) and other measurement errors; $u_{i}$ is a one-sided i.i.d. random error term $\left(u_{i} \geq 0\right) ; u_{i} \sim N^{+}\left(0, \sigma_{u}^{2}\right)$. The variance parameters of the model are computed as follows:

$$
\sigma_{s}^{2}=\sigma_{v}^{2}+\sigma_{u}^{2} ; \lambda=\frac{\sigma_{u}^{2}}{\sigma_{v}^{2}} ; \gamma=\frac{\lambda^{2}}{1+\lambda^{2}}=\frac{\sigma_{u}^{2}}{\sigma_{v}^{2}}
$$

where $\lambda$ is used for testing the presence of technical inefficiency and $\gamma$ measures the general effect of technical inefficiency with the variation of actual output (BravoUreta \& Pinheiro, 1997).

The stochastic output-oriented TE of each farm can be estimated by multiplying $\exp \left(-v_{i}\right)$ on both sides of equation (1). This yields equation (2) as follows:

$$
y_{i}^{\circ}=f\left(X_{i}, Z_{i}, \beta, \alpha, \delta\right) \exp \left(-u_{i}\right)=y_{i} \exp \left(-v_{i}\right)
$$

where $y_{i}^{\circ}$ is the actual output of the $i$-th farm adjusted for $v_{i}$, the statistical noise effect (Bravo-Ureta \& Rieger, 1991).

The TE measure is captured by the expression:

$$
\begin{aligned}
\mathrm{TE}_{\mathrm{i}}=\exp \left(-u_{i}\right) & =\frac{y_{i} \exp \left(-v_{i}\right)}{f\left(X_{i}, Z_{i}, \beta, \alpha, \delta\right)} \\
& =\frac{y_{i}}{f\left(X_{i}, Z_{i}, \beta, \alpha, \delta\right) \exp \left(v_{i}\right)}
\end{aligned}
$$

Where $u_{i} \geq 0$ and $0 \leq \exp \left(-u_{i}\right) \leq 1 . u_{i}$ is predicted by the conditional expectation of $u_{i}$, given the value of random composed error term $\left(v_{i}-u_{i}\right)$ (Jondrow et al., 1982). Based on this together with the given multiplicativity of the production frontier model in equation (1), Battese and Coelli (1988) proposed the TE measure as:

$$
\mathrm{TE}_{\mathrm{i}}=\mathrm{E}\left[\exp \left\{-u_{i}\right\} \mid\left(v_{i}-u_{i}\right)\right]
$$

In this study, we use the translog functional form, which is widely applied to estimate the stochastic production frontier (Coelli et al., 2005) and to measure environmental efficiency (Reinhard et al., 2000; Reinhard et al., 1999; Reinhard \& Thijssen, 2000). Equation (1) is then re-expressed in translog form as follows:

$$
\begin{aligned}
\ln Y_{i}= & \beta_{0}+\sum_{k} \beta_{k} \ln X_{k}+\sum_{m} \alpha_{m} \ln Z_{m} \\
& +\frac{1}{2} \sum_{k} \sum_{n} \beta_{k n} \ln X_{k} \ln X_{n}+\frac{1}{2} \sum_{m} \sum_{h} \alpha_{m h} \ln Z_{m} \ln Z_{h} \\
& +\sum_{k} \sum_{n} \delta_{k n} \ln X_{k} \ln X_{m}+v_{i}-u_{i}
\end{aligned}
$$

where $\ln Y i$ represents the natural logarithm of the output of the $i$-th farm.

$\mathrm{EE}$ is considered as one facet of TE because EE only estimates the possible reduction of bad inputs while input-oriented TE considers all inputs. A farm that is 
considered to be technically efficient is necessarily environmentally efficient. For this reason, Reinhard et al. (2000); and Reinhard et al. (1999) proposed setting $u_{i}$ equal to zero and replacing all bad inputs $Z_{i m}$ in equation (5) with $\Phi Z_{i m}$, where $\Phi$ is the EE score, in order to estimate EE. As a result, the reduction of bad inputs at the production frontier are adjusted for statistical noise $v_{i}$. This measure is more in line with the practical demands of farmers, whose economic goal is to expand output to the production frontier and reduce bad inputs to optimal levels.

The EE of the $i$-th farm is obtained by replacing $Z_{\text {im }}$ in equation (5) with $\Phi Z_{\text {im }}$ and setting $u_{i}=0$, which yields

$$
\begin{aligned}
& \ln Y_{i}=\beta_{0}+\sum_{k} \beta_{k} \ln X_{k}+\sum_{m} \alpha_{m} \ln \Phi Z_{m} \\
& \quad+\frac{1}{2} \sum_{k} \sum_{n} \beta_{k n} \ln X_{k} \ln X_{n}+\frac{1}{2} \sum_{m} \sum_{h} \alpha_{m n} \ln \Phi Z_{m} \ln \Phi Z_{h} \\
& \quad+\sum_{k} \sum_{n} \delta_{k n} \ln X_{k} \ln \Phi Z_{m}+v_{i}
\end{aligned}
$$

As defined Section 1, EE is the ability to reduce bad inputs to an optimal level on the production frontier, holding the output and normal inputs constant (Figure 1 and $2)$. As such, the output in equation (6) is considered to be equal to that in equation (5). Setting equations (6) and (5) equal to one another yields

$$
\begin{aligned}
& \sum_{m} \alpha_{m} \ln \Phi Z_{m}-\sum_{m} \alpha_{m} \ln Z_{m} \\
& +\frac{1}{2} \sum_{m} \sum_{h} \alpha_{m h} \ln \Phi Z_{m} \ln \Phi Z_{h}-\frac{1}{2} \sum_{m} \sum_{h} \alpha_{m h} \ln Z_{m} \ln Z_{h} \\
& +\sum_{k} \sum_{m} \delta_{k m} \ln X_{k} \ln \Phi Z_{m}-\sum_{k} \sum_{m} \delta_{k m} \ln X_{k} \ln Z_{m}+u_{i}=0
\end{aligned}
$$

It should be noted that $\ln \Phi_{\mathrm{i}}=\ln \Phi_{\mathrm{i}} \mathrm{Z}_{\mathrm{im}}-\ln \mathrm{Z}_{\mathrm{im}}$

$$
=\ln \left(\frac{\Phi_{\mathrm{i}} \mathrm{Z}_{\mathrm{im}}}{\mathrm{Z}_{\mathrm{im}}}\right)=\ln E E_{i} \text {. Some manipulation of equation }(7)
$$

yields

$$
a_{i}\left(\ln E E_{i}\right)^{2}+b_{i}\left(\ln E E_{i}\right)+u_{i}=0
$$

where $a_{i}=\frac{1}{2} \sum_{m} \sum_{h} \alpha_{m h} \forall a_{i} \neq 0$;

$$
\begin{aligned}
& b_{i}=\sum_{m} \alpha_{m}+\frac{1}{2} \sum_{m} \sum_{h} \alpha_{m h}\left(\ln Z_{m}+\ln Z_{h}\right) \\
& +\sum_{k} \sum_{m} \delta_{k m} \ln X
\end{aligned}
$$

From equation (8), we can then calculate $\mathrm{EE}_{\mathrm{i}}$ as follows:

$$
E E_{i}=\exp \left(\frac{-b_{i} \pm \sqrt{b_{i}^{2}-4 a_{i} u_{i}}}{2 a_{i}}\right)
$$

According to Reinhard et al. (1999), Reinhard et al. (2000) and Kouser and Mushtaq (2010), because a technically efficient firm must be environmentally efficient, we choose only the solution with $+\sqrt{ }\left(u_{i}=0 \Rightarrow E E_{i}=T E_{i}\right.$ $=1$ ). As a result, $\mathrm{EE}$ is obtained by the following expression:

$$
E E_{i}=\exp \left(\frac{-b_{i}+\sqrt{b_{i}^{2}-4 a_{i} u_{i}}}{2 \alpha_{i}}\right)
$$

Following the same procedure, we can estimate pesticide use efficiency as a non-radial contraction of pesticide cost.

Figure 1 and 2 are the graphical illustrations that provide better understanding about the production frontier and the measures of technical and environmental efficiency in surface and cross-section, respectively.

Figure 1 represents the best practice frontier by the increasing, quasi-concave surface $\mathrm{OX}_{R} R^{F} Z_{R}$. Point $R$ is the observed farm that has output level $Y_{R}$ produced using $X_{R}$ and $Z_{R}$. The surface ABCR is the identical output quantity, $Y_{R}$, of farm $R$. From this surface, we can derive figure 2 as cross-sectional production frontier in normal (X) and bad (Z) input space, holding output level constant at $Y_{R}$.

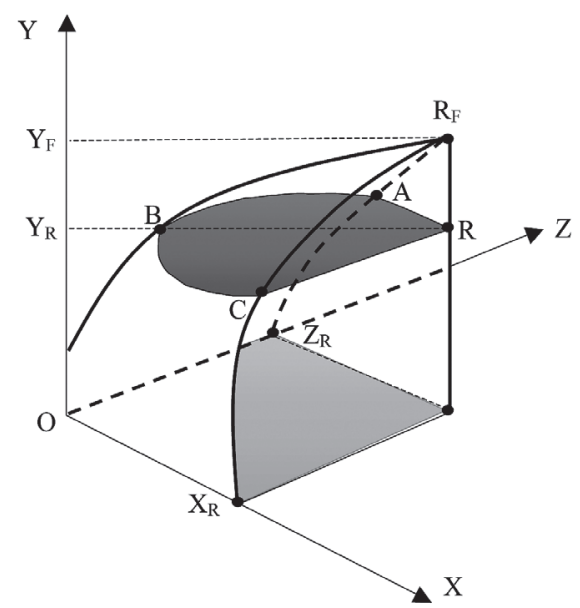

Fig. 1. 3-D graphical illustration of technical and environmental efficiency measures.

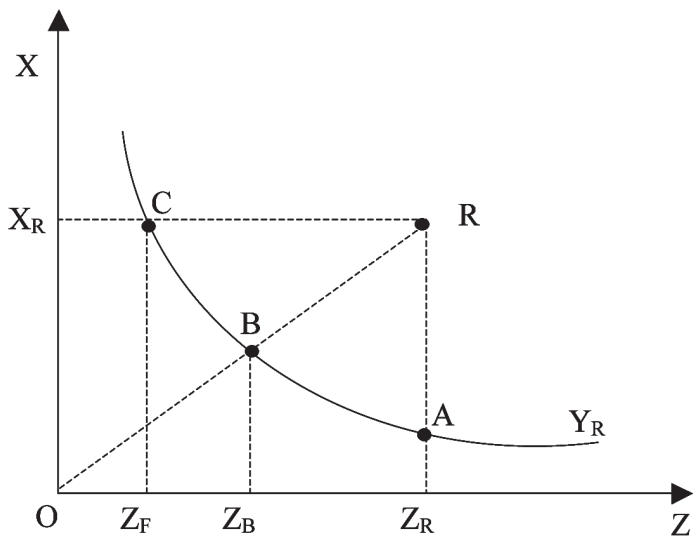

Fig. 2. Cross-sectional graph of input-oriented technical and environmental efficiency measures. 
In figure 1, it is easy to obtain a measure of outputoriented technical efficiency, which is provided by the ratio of $\left|O Y_{R}\right| /\left|O Y_{F}\right|$. In figure 1, it is also possible to measure input-oriented technical efficiency as a radial contraction by the ratio of $\left|Y_{R} B\right| /\left|Y_{R} R\right|$. In figure 2 , such measure (input-oriented technical efficiency) is provided by $|O B| /|O R|$.

Environmental efficiency, in turn, is measured as the ratio of minimum possible input use to observed input level, which is reflected by $\left|O Z_{F}\right| /\left|O Z_{R}\right|$ in figure 2 . Stata software version 11 was used to estimate the stochastic production frontier and to calculate the TE and EE.

\section{COLLECTION AND CHARACTERISTICS OF DATA}

In 2012, An Giang Province contributed 3,941,526 tons of rice with a total cultivated area of 625,862 hectares, which was more than $16 \%$ of the VMD's total production from approximately 15\% of the total cultivation area. It is the second largest rice producer in the VMD after Kien Giang Province (GSO, 2013; SOAG, 2013).

In March 2011, An Giang Province commenced adopting ecological engineering in rice production, starting with five districts as demonstration plots under the project "Technical Training and Demonstration of Ecological Engineering on Paddy Fields to Attract Natural Enemies against Pests and Brown PlantHoppers". In the winter and spring of 2011-2012, four other districts were selected to integrate ecological engineering, thus expanding the initial 50 hectares of farmland by another 40 (PPDAG, 2012). Since then, hundreds of farmers throughout the province have adopted ecological engineering.

Based on the suggestions from local authorities, the primary data of this study are collected in four districts (Thoai Son, Chau Doc, An Phu, and Tan Chau) where were considered to be the most crowded farmers who apply ecological engineering in their rice production. We conducted face-to-face interviews with 199 farmers using the structured questionnaires. In which, 74 farmers had adopted ecological engineering and 125 farmers used traditional methods of producing rice.

Based on the moisture content, the rice output quantities of production function are catalogued two metrics: "wet" output has moisture content ranging from 20 to $25 \%$ and "dry" output has moisture content of around $14 \%$. In the sample, since we found that approximately $75 \%$ of the farmers sold their products "wet" after harvesting, the 'wet' metric of output quantity was applied.

There are two types of inputs used in the stochastic frontier analysis, namely bad and normal one. The former includes active nutrients of nitrogen in kilograms per hectare (kg/ha), active nutrients of phosphorus and potash in $\mathrm{kg} / \mathrm{ha}$, and total pesticide and energy used in cost/ ha. The latter includes seed quantity (from market and self-production), family labors capital (calculated based on the revaluation principle of capital stocks), and other expenditures (including harvester services, and pumping services), which were all measured in hectares. Table 1 describes the characteristics of the data set used in detail.

Table 1 shows that the output levels of eco rice (at the mean value of $7,097 \mathrm{~kg} / \mathrm{ha}$ ) is insignificant lower than that of normal rice (at the mean of $7,147 \mathrm{~kg} / \mathrm{ha}$ ), while pesticide costs of eco rice are about one million VND lower than that of normal rice. The difference in pesticide costs is significant at the $1 \%$ level, showing that the model of ecological engineering had positive effects on environment.

\section{RESULTS}

Prior to estimating the stochastic production frontier using the translog form, we have to test it against Cobb-Douglas form (Khalil, 2005; Reinhard et al., 2000). Based on likelihood ratio of 55.44, which is larger than $\chi_{(28.1 \%)}^{2}$ critical value of 48.27 , suggesting that we reject

Table 1. Characteristics of data set ${ }^{\Psi}$ used for environmental efficiency measurement

\begin{tabular}{|c|c|c|c|c|c|c|c|}
\hline \multirow{2}{*}{ Indicator } & \multicolumn{3}{|c|}{ Eco rice } & \multicolumn{3}{|c|}{ Normal rice } & \multirow{2}{*}{ T-value } \\
\hline & Mean & Min & $\operatorname{Max}$ & Mean & Min & $\operatorname{Max}$ & \\
\hline Output quantity $^{\dagger}(\mathrm{Y})$ & 7097.03 & 5902.78 & 8865.43 & 7147.79 & 5015.43 & 8217.59 & -0.51 \\
\hline \multicolumn{8}{|l|}{ Bad inputs } \\
\hline Nitrogen quantity ${ }^{\dagger}\left(\mathrm{Z}_{1}\right)$ & 101.73 & 50.62 & 152.01 & 112.54 & 70.85 & 176.85 & $-3.27 * * *$ \\
\hline Potash and phosphorus ${ }^{\dagger}\left(\mathrm{Z}_{2}\right)$ & 119.98 & 63.27 & 192.52 & 116.12 & 74.13 & 199.85 & 1.17 \\
\hline Pesticide $\operatorname{cost}^{\omega}\left(\mathrm{Z}_{3}\right)$ & 3570.76 & 1697.53 & 7330.25 & 4539.16 & 2341.82 & 10030.86 & $-4.65 * * *$ \\
\hline Energy $\operatorname{costs}^{\omega}\left(\mathrm{Z}_{4}\right)$ & 1511.11 & 430.17 & 2808.06 & 1576.32 & 614.53 & 3169.14 & -0.81 \\
\hline \multicolumn{8}{|l|}{ Normal inputs } \\
\hline Seed quantity ${ }^{\dagger}\left(X_{1}\right)$ & 100.18 & 23.15 & 216.05 & 153.61 & 11.57 & 366.51 & $-5.11^{* * *}$ \\
\hline $\operatorname{Labor}^{\omega}\left(X_{2}\right)$ & 261.02 & 188.27 & 335.65 & 245.76 & 169.75 & 349.15 & $2.83^{* * *}$ \\
\hline $\operatorname{Others}^{\omega}\left(\mathrm{X}_{3}\right)$ & 5262.18 & 2338.70 & 8046.77 & 8257.51 & 3233.00 & 24634.27 & $-8.97 * * *$ \\
\hline
\end{tabular}

$\omega$ : in thousand VND/ha; $\quad \dagger$ : kg/ha; $\Psi$ : average values for one year;

*** indicates the $1 \%$ level of significance

Source: Own estimates, data available from the authors 
the null hypothesis or the restricted model is inappropriate to our data. We therefore decided to use the translog function for MLE regression.

We now estimate the stochastic frontier production and calculate EE. Table 2 shows the results of MLE regression models that estimate $\mathrm{TE}$ and $\mathrm{EE}$.

It is clear that the estimated value of $\lambda$ is non-zero $(\lambda=5.07)$. The null hypothesis of the inefficiency absence is rejected at the significant level of $0.1 \%$ using Z-statistic ( $\mathrm{z}$-value $=453.14$ ) or using $\mathrm{LR}$-test $(\mathrm{LR}$ value $=34.35$ ), showing the existence of technical inefficiency for these rice farmers (see Table 2). This result is consistent with Khai and Yabe (2011) and Kompas (2004). Based on the estimated value of $\gamma=0.9626$, which means

Table 2. Coefficients of translog function form with MLE

\begin{tabular}{|c|c|c|c|c|c|}
\hline \multirow{2}{*}{ Predictor } & \multicolumn{2}{|c|}{ MLE } & \multicolumn{3}{|c|}{ MLE } \\
\hline & Coefficient & Std. error & Predictor & Coefficient & Std. error \\
\hline $\ln Z_{1}$ & 8.4285 & 2.6322 & $\ln Z_{2} \ln X_{2}$ & 0.0045 & 0.3538 \\
\hline $\ln Z_{2}$ & -0.2990 & 2.0779 & $\ln Z_{2} \ln X_{3}$ & -0.0382 & 0.0970 \\
\hline $\ln Z_{3}$ & -0.5218 & 1.2569 & $\left(\ln Z_{3} \ln Z_{3}\right) / 2$ & -0.1367 & 0.0778 \\
\hline $\ln Z_{4}$ & 0.1494 & 1.1283 & $\ln Z_{3} \ln Z 4$ & -0.0791 & 0.0470 \\
\hline $\ln X_{1}$ & -0.5249 & 0.6797 & $\ln Z_{3} \ln \mathrm{X}_{1}$ & 0.0279 & 0.0288 \\
\hline $\ln X_{2}$ & 4.0396 & 6.1533 & $\ln Z_{3} \ln X_{2}$ & 0.3145 & 0.1816 \\
\hline $\ln X_{3}$ & 0.8232 & 1.5476 & $\ln Z_{3} \ln X_{3}$ & -0.0298 & 0.0638 \\
\hline$\left(\ln Z_{1} \ln Z_{1}\right) / 2$ & -1.0024 & 0.1979 & $\left(\ln Z_{4} \ln Z_{4}\right) / 2$ & -0.0105 & 0.0534 \\
\hline $\ln Z_{1} \ln Z_{2}$ & -0.0173 & 0.1399 & $\ln Z_{4} \ln X_{1}$ & -0.0716 & 0.0296 \\
\hline $\ln Z_{1} \ln Z_{3}$ & 0.0141 & 0.0965 & $\ln Z_{4} \ln X_{2}$ & 0.0969 & 0.1332 \\
\hline $\ln Z_{1} \ln Z_{4}$ & -0.0839 & 0.0767 & $\ln Z_{4} \ln X_{3}$ & 0.0326 & 0.0600 \\
\hline $\ln Z_{1} \ln X_{1}$ & 0.1263 & 0.0455 & $\left(\ln X_{1} \ln X_{1}\right) / 2$ & -0.0259 & 0.0163 \\
\hline $\ln Z_{1} \ln X_{2}$ & -0.7918 & 0.3329 & $\ln \mathrm{X}_{1} \ln \mathrm{X}_{2}$ & 0.079 & 0.0942 \\
\hline $\ln Z_{1} \ln X_{3}$ & 0.1010 & 0.1212 & $\ln X_{1} \ln X_{3}$ & -0.0184 & 0.0247 \\
\hline$\left(\ln Z_{2} \ln Z_{2}\right) / 2$ & -0.2004 & 0.2186 & $\left(\ln \mathrm{X}_{2} \ln \mathrm{X}_{2}\right) / 2$ & -0.5827 & 1.0421 \\
\hline $\ln Z_{2} \ln Z_{3}$ & 0.1065 & 0.0827 & $\ln \mathrm{X}_{2} \ln \mathrm{X}_{3}$ & -0.0522 & 0.2089 \\
\hline $\ln Z_{2} \ln Z_{4}$ & 0.1135 & 0.0566 & $\left(\ln X_{3} \ln X_{3}\right) / 2$ & -0.0724 & 0.1005 \\
\hline $\ln Z_{2} \ln X_{1}$ & 0.0129 & 0.0308 & Constant & -24.2995 & 22.7102 \\
\hline$\lambda$ & 5.0752 & 0.0112 & Wald $\chi^{2}$ value & 387.16 & \\
\hline$\gamma$ & 0.9626 & & LR test $\sigma_{\mathrm{u}}=0$ & 34.35 & \\
\hline Log Likelihood & 265.96 & & & & \\
\hline
\end{tabular}

Source: Own estimates, data available from the authors

Table 3. Comparison of environmental efficiency between eco and normal rice

\begin{tabular}{|c|c|c|c|c|c|}
\hline \multirow{2}{*}{ EE levels } & \multicolumn{2}{|c|}{ Eco rice } & \multicolumn{3}{|c|}{ Normal rice } \\
\hline & No. farmer & Percentage & & No. farmer & Percentage \\
\hline$\geq 90$ & 30 & 40.54 & & 51 & 40.80 \\
\hline $80-90$ & 22 & 29.73 & & 42 & 33.60 \\
\hline $70-80$ & 16 & 21.62 & & 21 & 16.80 \\
\hline $60-70$ & 6 & 8.11 & & 5 & 4.00 \\
\hline$\leq 60$ & 0 & 0.00 & & 6 & 4.80 \\
\hline Mean EE & \multicolumn{2}{|c|}{85.54} & \multicolumn{3}{|c|}{84.54} \\
\hline Min & \multicolumn{2}{|c|}{67.92} & \multicolumn{3}{|c|}{52.96} \\
\hline $\operatorname{Max}$ & \multicolumn{2}{|c|}{98.42} & \multicolumn{3}{|c|}{98.34} \\
\hline Standard Deviation & \multicolumn{2}{|c|}{8.97} & \multicolumn{3}{|c|}{10.94} \\
\hline $\mathrm{T}$-value & \multicolumn{5}{|c|}{0.66} \\
\hline
\end{tabular}

Source: Own estimates, data available from the authors 
that $96.29 \%$ of the total variation of output levels is due to technical inefficiency.

We now turn to estimate environmental, technical and pesticide use efficiency. As expected from the eco rice model, its environmental and pesticide use efficiency are higher than that of normal rice. The EE scores of both eco and normal rice are presented in Table 3.

Table 3 shows that although the average EE of eco rice $(85.54 \%)$ is slightly higher than that of normal rice (84.54\%), this difference is insignificant at the $5 \%$ level. These values indicate that eco rice farmers and normal rice farmers can reduce approximately $14.46 \%$ and $15.46 \%$, respectively, of their current use of bad inputs if holding output and normal inputs constant. However, the normal rice farmers had greater variation in EE scores than the eco rice ones. In fact, there was about $5 \%$ of the normal rice farmers who had EE scores distributed below $60 \%$ while none of the cases were found for the eco rice farmers. This result partially implies that the introduction of ecological engineering into rice production had positive effects on the environment.
In order to produce more holistic policy implications to disseminate the model, we also estimated the ability to contract only pesticide use (pesticide use efficiency), given other inputs and output constant, and to maximize actual output levels (output-oriented TE), given both bad and normal inputs. Table 4 and 5 illustrate the pesticide use efficiency and TE results, respectively, of both eco rice farmers and normal rice farmers.

It is clearly shown in Table 4 that the eco rice farmers had a significantly higher pesticide use efficiency than those of normal rice. The average pesticide use efficiency of eco rice was $33.95 \%$ and $20.77 \%$ for normal rice, suggesting that the eco rice and normal rice farmers could realize to reduce about $72.05 \%$ and $79.23 \%$, respectively, of their current use of pesticide if holding other inputs and output constant.

We now turn to estimate the output-oriented TE, which is summarized in Table 5 below:

Table 5 shows that the average output-oriented TE is a bit higher for eco rice (92.24\%) than that for normal rice $(92.17 \%)$, but in general, the difference is insignifi-

Table 4. Comparison of pesticide use efficiency between eco and normal rice

\begin{tabular}{|c|c|c|c|c|c|}
\hline \multirow{2}{*}{ Levels } & \multicolumn{2}{|c|}{ Eco rice } & \multicolumn{3}{|c|}{ Normal rice } \\
\hline & No. farmer & Percentage & & No. farmer & Percentage \\
\hline$\geq 70$ & 5 & 6.76 & & 4 & 3.20 \\
\hline $60-70$ & 4 & 5.40 & & 2 & 1.60 \\
\hline $50-60$ & 8 & 10.81 & & 4 & 3.20 \\
\hline $40-50$ & 8 & 10.81 & & 6 & 4.80 \\
\hline $30-40$ & 12 & 16.22 & & 14 & 11.20 \\
\hline $20-30$ & 15 & 20.27 & & 17 & 13.60 \\
\hline$\leq 20$ & 22 & 29.73 & & 78 & 62.40 \\
\hline Mean & \multicolumn{2}{|c|}{33.95} & \multicolumn{3}{|c|}{20.77} \\
\hline Min & \multicolumn{2}{|c|}{6.37} & \multicolumn{3}{|c|}{2.67} \\
\hline $\operatorname{Max}$ & \multicolumn{2}{|c|}{80.25} & \multicolumn{3}{|c|}{85.74} \\
\hline Standard deviation & \multicolumn{2}{|c|}{18.95} & \multicolumn{3}{|c|}{17.17} \\
\hline T-value & \multicolumn{5}{|c|}{5.03} \\
\hline
\end{tabular}

Table 5. Comparison of technical efficiency between eco and normal rice

\begin{tabular}{|c|c|c|c|c|c|}
\hline \multirow{2}{*}{ TE levels } & \multicolumn{2}{|c|}{ Eco rice } & \multicolumn{3}{|c|}{ Normal rice } \\
\hline & No. farmer & Percentage & & No. farmer & Percentage \\
\hline$\geq 90$ & 53 & 71.62 & & 94 & 75.20 \\
\hline $80-90$ & 21 & 28.38 & & 21 & 16.80 \\
\hline$\leq 80$ & 0 & 0.00 & & 10 & 8.00 \\
\hline Mean TE & \multicolumn{2}{|c|}{92.24} & \multicolumn{3}{|c|}{92.17} \\
\hline Min & \multicolumn{2}{|c|}{80.21} & \multicolumn{3}{|c|}{71.16} \\
\hline Max & \multicolumn{2}{|c|}{99.31} & \multicolumn{3}{|c|}{99.04} \\
\hline Standard deviation & \multicolumn{2}{|c|}{5.14} & & \multicolumn{2}{|c|}{6.37} \\
\hline T-value & & & 0.09 & & \\
\hline
\end{tabular}

Source: Own estimates, data available from the authors 
cant at the $5 \%$ level. These values of TE indicate that the eco rice and normal rice farmers could expand their output levels about $7.76 \%$ and $7.83 \%$, respectively, holding all inputs constant. The variation of TE scores was also greater for the normal rice than for the eco rice. As shown in Table 4 that $8 \%$ of the normal rice farmers had the TE scores distributed under 80\%, suggesting that those farmers could realize to expand their output levels by more than $20 \%$. Whereas, as regards the eco rice, $100 \%$ of the farmers had the TE scores distributed above $80 \%$.

In conclusion, although the comprehensive $\mathrm{EE}$ and TE scores of eco rice insignificantly differ from that of normal rice, the pesticide use efficiency of eco rice was significantly higher. In addition, based on the overall distribution and variation and the significant lower use of pesticides, we can suggest that the ecologically engineered rice production is more environmentally friendly and technically efficient than conventional rice cultivation.

\section{CONCLUSIONS}

In 2009, ecological engineering rice production was introduced in the Mekong Delta of Vietnam coordinated by the IRRI. Despite its positive effects on environmental protection, the model was not so popular even after four years of implementation. Results from our descriptive statistics showed that the output quantity of eco rice production was slightly but insignificant lower than that of normal rice (approximately 7,097 kg/ha and 7,147 kg/ ha, respectively), while the costs of pesticide were much lower for eco rice than for normal rice.

We used the approach of stochastic frontier analysis to estimate and compare the EE, output-oriented TE and pesticide use efficiency of ecologically engineered rice cultivation with that of traditional rice cultivation. We estimated that the average comprehensive EE score of eco rice cultivation was approximately $1 \%$ higher than that of normal rice. Similarly, the average TE was also higher for eco rice (92.24\%) than for normal rice (92.17\%). Although these differences were insignificant, the variations of both the $\mathrm{EE}$ and $\mathrm{TE}$ scores were greater for the normal rice than for the eco rice. Further, the pesticide use efficiency of eco rice was significantly higher than that of normal rice. These results suggested that ecologically engineered rice cultivation was more environmentally friendly and to some extent had more potential to expand actual output to the production function frontier.

\section{ACKNOWLEDGMENTS}

We would like to express our deep gratitude to $\mathrm{Mr}$. Nguyen Van Hong, a technical expert at the Provincial Agricultural Extension Center of An Giang Province and Ms. Lu Thi Kim Dung, a technical expert at the District Extension Station of Thoai Son District. We are also thankful to Ms. Pham Thi Nhu, a technical expert at the
District Extension Station of Chau Thanh District who organized the meetings and face-to-face interviews with farmers and also provided valuable for the study.

\section{REFERENCES}

Battese, G. E., \& T. J. Coelli 1988 Prediction of firm-level technical efficiencies with a generalized frontier production function and panel data. Journal of econometrics, 38(3): 387-399

Belbase, K., \& R. Grabowski 1985 Technical efficiency in Nepalese agriculture. The Journal of Developing Areas, 515526

Bravo-Ureta, B. E., \& L. Rieger 1991 Dairy farm efficiency measurement using stochastic frontiers and neoclassical duality. American Journal of Agricultural Economics, 73(2): 421428

Bravo-Ureta, B. E., \& A. E. Pinheiro 1997 Technical, economic, and allocative efficiency in peasant farming: evidence from the Dominican Republic. The Developing Economies, 35(1): 48-67

Coelli, T. J., D. S. P. Rao, C. J. O’Donnell, \& G. E. Battese 2005 An introduction to efficiency and productivity analysis. Springer

Dung, N. H., \& T. T. T. Dung 1999 Economic and health consequences of pesticide use in paddy production in the Mekong Delta, Vietnam. Economy and environment program for Southeast Asia (EEPSEA)

Ecobichon, D. J. 2001 Pesticide use in developing countries. Toxicology, 160(1-3), 27-33 doi: http://dx.doi.org/10.1016/ S0300-483X(00)00452-2

Färe, R., S. Grosskopf, C. K. Lovell, \& C. Pasurka 1989 Multilateral productivity comparisons when some outputs are undesirable: a nonparametric approach. The review of economics and statistics, 90-98

GSO 2013 Statistical yearbook of Vietnam

Heong KL, H. B., editors 2009 Planthoppers: new threats to the sustainability of intensive rice production systems in Asia. Los Baños (Philippines): International Rice Research Institute, 460

Jondrow, J., C. Knox Lovell, I. S. Materov, \& P. Schmidt 1982 On the estimation of technical inefficiency in the stochastic frontier production function model. Journal of econometrics, 19(2): 233-238

Khai, H. V., \& M. Yabe 2011 Technical efficiency analysis of rice production in Vietnam. Journal of ISSAAS, 17(1): 135-146

Khalil, A. M. 2005 A cross section estimate of translog production function: Jordanian manufacturing industry

Kompas, T. 2004 Market Reform, Productivity and Efficiency in Vietnamese Rice Production. International and Development Economics Working Paper 04-4

Kouser, S., \& K. Mushtaq 2010 Environmental Efficiency Analysis of Basmati Rice Production in Punjab, Pakistan: Implications for Sustainable Agricultural Development. The Pakistan Development Review, 57-72

Pittman, R. W. 1981 Issue in pollution control: interplant cost differences and economies of scale. Land economics, 1-17

Pittman, R. W. 1983 Multilateral productivity comparisons with undesirable outputs. The Economic Journal, 883-891

PPDAG 2012 Project on technical training and demonstration of ecological engineering on paddy field to attract natural enemies against pests and brown plant hoppers Final report submitted to Department of Science and Technology, An Giang Province, Vietnam

Reinhard, S., C. Knox Lovell, \& G. J. Thijssen 2000 Environmental efficiency with multiple environmentally detrimental variables; estimated with SFA and DEA. European Journal of Operational Research, 121(2): 287-303

Reinhard, S., C. K. Lovell, \& G. Thijssen 1999 Econometric estimation of technical and environmental efficiency: an application to Dutch dairy farms. American Journal of Agricultural 
Economics, 81(1): 44-60

Reinhard, S., \& G. Thijssen 2000 Nitrogen efficiency of Dutch dairy farms: a shadow cost system approach. European Review of Agricultural Economics, 27(2): 167-186
Shapiro, K. H., \& J. Müller 1977 Sources of technical efficiency: the roles of modernization and information. Economic Development and Cultural Change, 293-310 SOAG 2013 Statistical yearbook of An Giang Province 2012 